\title{
Engagement in Practice: The Vocabulary of Community Development as an Indicator of a Participatory Mind-set
}

\section{Dr. Howard L. Greene, Ohio State University}

Howard L. Greene directs K-12 Education Outreach for the College of Engineering at The Ohio State University, bringing university research and teaching intersections to the K-12 community, especially those underserved and/or underrepresented. Dr. Greene also chairs the Humanitarian Engineering Advisory and spearheads an initiative in Humanitarian Development and Innovation at OSU. Prior to Ohio State, Dr. Greene worked for 12 years in medical device development and later in STEM education and outreach at Battelle in Columbus, Ohio. Prior to Battelle, Dr. Greene was a professor of Electronics Engineering Technology at DeVry University in Columbus. Dr. Greene received the Ph.D. and M.S. degrees from The Ohio State University in Biomedical Engineering and Electrical Engineering, respectively.

\section{Mr. Kaleb Eldridge, Heart to Honduras}

Kaleb has seven years of experience living in rural Honduras and working in asset-based community development with the development organization Heart to Honduras. He is currently a candidate at the University of Pittsburgh's Graduate School of Public and International Affairs for a Master's in International Development with a concentration in NGOs and Civil Society. Meanwhile, he and his wife Stacey continue to work with Heart to Honduras at a distance.

\section{Patrick John Sours, Ohio State University}

Patrick is a graduate student in Food, Agricultural and Biological Engineering. Patrick received a B.S. in Civil Engineering from The Ohio State University with a minor in Humanitarian Engineering. Patrick's graduate research focus is international development through engineering. His main research project is Maji Marwa: A Sustainable and Resilient Community Project. Patrick has been involved with Humanitarian Engineering projects at Ohio State for the past seven years. He has worked on project in Guatemala, Honduras, India and Tanzania. 


\section{Engagement in Practice: The Vocabulary of Community Development as an Indicator of a Participatory Mindset}

\section{Introduction}

Since 2005, at The Ohio State University (OSU), an ecosystem of offerings in Humanitarian Engineering has emerged, from a themed living-learning community, Humanitarian Engineering Scholars, to a humanitarian engineering minor supported by several core courses and numerous humanitarian engineering student organizations. Since then, what were a few short-term study abroad opportunities evolved into eight full-fledged service learning programs with many executed in conjunction with local or global NGO/non-profit partners [1]. These expanded opportunities in service learning have been created in response to the increased student desire to improve the human condition for underserved populations around the world.

A critical challenge inherent in such work is balancing meaningful student learning with sustainable benefit to communities. Without this balance, well-intentioned programs run the risk of leaving communities worse off than when engagements began - 'disempowerment' in the name of 'transformative learning experiences'.

As an academic institution, we tend to let academic constructs dictate our processes in service learning. For example, schedules generally conform to the academic calendar, i.e., the beginnings and endings of semesters within a 9-month span, which is not necessarily what is best for communities or our NGO partners. Design curricula are often formed around experiencing a complete cycle of the engineering design process or demonstration of the application of certain engineering or business field-specific tools in project work [2]. Further, the tendency to work in disciplinary silos leads to difficulty in properly integrating fields outside engineering that are necessary in sustainable community development. These tendencies can lead to engagements that are "projectized", better meeting the needs of students and the academic community than partner communities.

\section{Vocabulary of Community Development}

For the past 2 years, the initiative in Humanitarian Development and Innovation (HDI) at OSU has facilitated a group of engineers involved in community development to come together more regularly, to form more cross-program and cross-discipline collaborations and be increasingly reflective of the work that we do with local and global partners. We have noticed that this thoughtful reflection has begun to transform our mindset as we have prioritized the importance of sustainable benefit to communities. That mindset change is exemplified in our vocabulary the words we use to honestly describe our efforts to others or ourselves. Specifically, the words that describe the attitudes we bring, the relationships we form, how we work together, the outcomes we experience and finally, the resultant feelings of the community, have all experienced a shift from left to right in Figure 1.

When the focus of service learning programs shifts towards what is best for sustained growth in partner communities, we tend to describe our work with more process vocabulary found on the right hand side of the figure than project vocabulary on the left hand side. For example, we build trust as we co-develop sustainable processes as opposed to create dependencies as we deliver product solutions to beneficiaries. Additionally, when we focus on communities, our relationships tend towards the right, e.g., more transparent, collaborative and participatory 
and less hidden, unilateral and paternalistic. The result is that communities we work with feel increasingly empowered, trusted, respected and affirmed (right side), as opposed to helpless, suspicious, ignored and patronized (left side).

\section{Community Development Vocabulary}

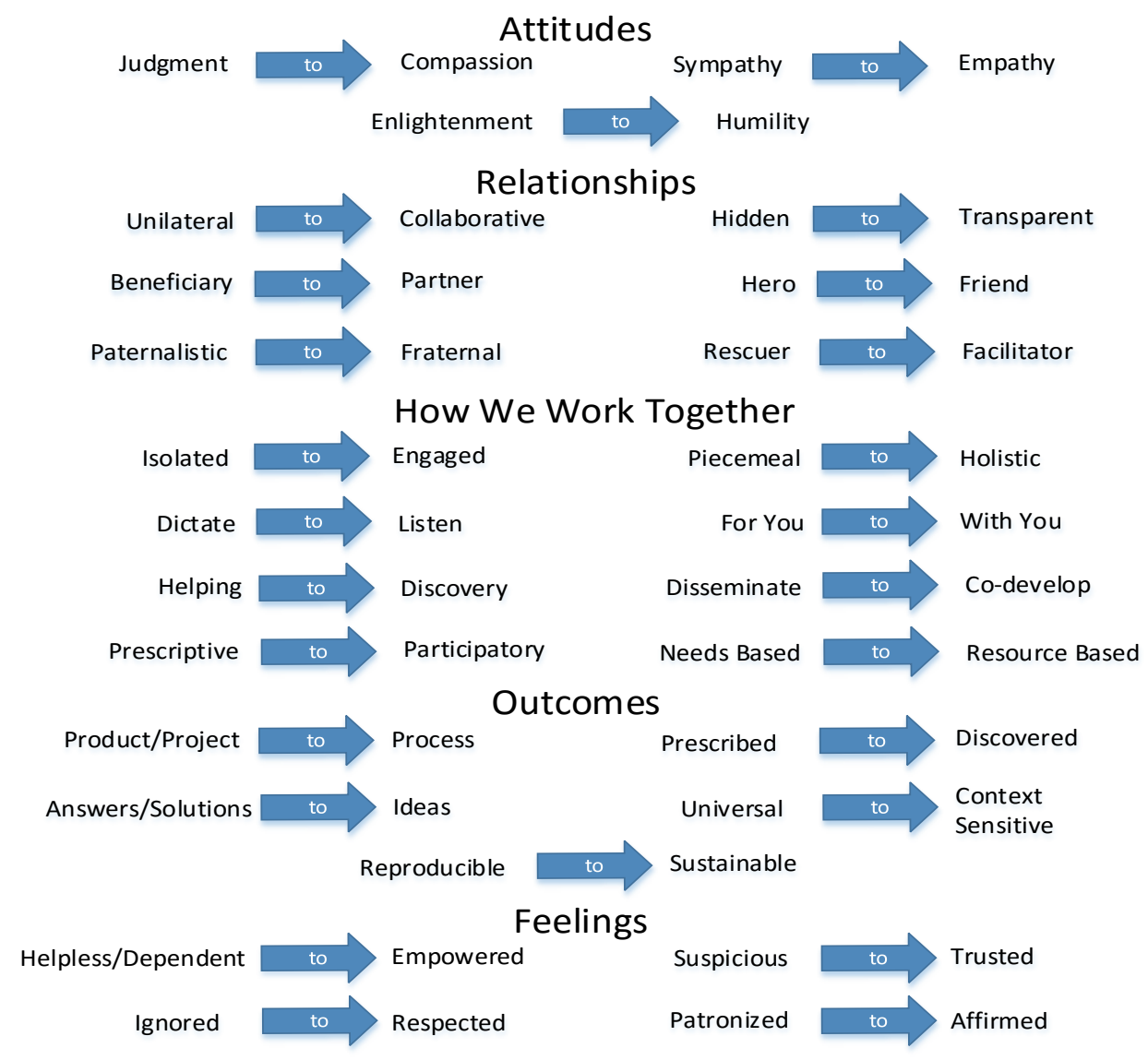

Figure 1. Vocabulary that describes our engagements in community development. As we focus on communities, vocabulary transitions from left to right.

Two things are important to note. First, whether our vocabulary is aspirational or objective reality needs to be differentiated. For example, few programs would aspire to have an attitude of 'enlightenment', intentionally working to form 'paternalistic' relationships that cause communities to feel more 'helpless/dependent'. However, in many cases, an honest, but critical assessment of program outcomes will yield post-engagement realities that differ from the intentions at program inception. Second, the left vs. right sides of the transitions (designated by arrows in Figure 1) are not meant to indicate binary conditions, e.g., either 'unilateral' or 'collaborative', but a continuum from left to right, as we increasingly focus on communities.

\section{Case Study}

The following case study describes a 2-year service learning program at OSU that, upon postreflection, became the motivation for a recent transition to more participatory and communityfocused service learning efforts. The contrast in vocabulary (left vs right hand side of Figure 1) that we experienced is given in bold-faced text in the following narrative. 
In 2014, a 2-year internal university grant was awarded for multi-disciplinary engineering capstone teams to design and construct "sustainable homes" for an NGO partner in Honduras. The process used was part of a more general three-phase academic construct developed for student teams to produce replicable solutions to basic needs in developing countries [3].

The intent of the Honduras Sustainable Housing initiative was to combine two elements: 1. The financial means for a Honduran family to obtain a home via an affordable mortgage loan combined with a subsidy provided by the in-country, faith-based community and 2 . A sustainable home. Each two semester (Sept. - May) program incorporated two team trips to Honduras. The purpose of the first trip, shortened because it occurred during the semester, was to give the team of undergraduate engineering and business students a mini cultural immersion and allow direct meetings with the community to gauge user needs and priorities related to housing in the NGO-selected rural village. The second was a two week implementation trip in May after the end of spring semester during which the student-designed 'pilot' home would be built.

During the first trip, we conducted a single 2-hour focus group session with about 25 community members in the elementary school. The very premise of the meeting was deficiency-oriented, i.e., needs based, as opposed to asset or resource based. It quickly became clear that gathering community members together in a neutral setting and asking them about housing experiences would be insufficient to gauge user needs. Representatives of more affluent families dominated the conversation and quickly took control, requesting home features like high-end bodegas (tool sheds) and electric stoves not found in any homes in the community. At the end of the session, we asked if anyone would allow us to tour their home so that we could witness firsthand how they utilized their living spaces. Our intent was to listen to community members describe features they wanted or deficiencies they perceived in their present homes. Those who agreed had waited patiently and silently in the back of the focus group room and seemed much more materially-poor than those who had dominated the focus group. We later found out that they believed we would fix their present homes (e.g., leaky roofs) if they simply showed them to us.

The dwellings that we toured had serious structural issues - many lacking four walls or having significant portions constructed out of plastic, cardboard and sticks. The aftermath of this experience was emotionally challenging as the team struggled to reconcile their relatively opulent lifestyles with the extreme material poverty they had just witnessed. However, instead of developing feelings of kinship towards community members, the short trip magnified contrasts and served to instill attitudes of sympathy (as opposed to empathy). Some students expressed the desire to rescue those they had seen from their situations while others reinforced judgments about those they had seen. None of these attitudes or relationships constitute a solid premise for working in a collaborative way with a community.

Upon return, the team faced the challenge of gathering adequate information to design a sustainable home from a four-day trip that included only few hours in the community. In order to sufficiently define the scope of the ensuing design effort and make the effort a project whose outcome was a sustainable home, the team had to make many assumptions. Most of those assumptions would prove difficult to validate in isolation - absent direct community interaction. The tendency of engineers during early stages of development is to make enough assumptions to come to closure on requirements and let design proceed. In this case, the attempt to draw a "neat" boundary around something inherently complex, e.g., information gleaned from a focus group in an early-stage relationship where even the context of the university students' presence 
was not known, resulted in incorrect assumptions. Furthermore, the project advisor (who had a product development background) encouraged the team to make such assumptions. In the drive for closure, the voice of the community, whose opinions had been gleaned from a single visit and appeared disparate and even inconsistent, was placed in the background. The voice of the faith based NGO, the in-country host, was elevated for the sake of simplicity and convenience.

The team's primary liaison between the first semester focus group trip and the second semester implementation trip was a compassionate pastor who worked for the NGO and had lived in Honduras for $30+$ years. His strong desire to see better conditions for rural Hondurans and his "futuristic pastor lens" often characterized communities as far more receptive to change than they really were. The information the team received through the pastor was potentially biased by his position and the appearance of having resources. Without opportunity for direct feedback from the community, the team relied upon indirect feedback from the pastor and their own personal opinions and value systems to fill the voids. The lack of continued direct engagement with the community transitioned an engaged, transparent, participatory and collaborative process and made it isolated, hidden, prescriptive and unilateral. The team struggled to fully understand the true needs and wants of the community. Key design drivers became material cost and environmental sustainability, assumed priorities that did not come from the community.

As described previously, academic schedules impose artificial constraints upon the community development process when students are involved. The student team knew that by the end of the implementation trip their student-designed home needed to be built so that a family could take residence. Further, it was not clear who would continue to work on the design the following year or even if there would be a 'handoff' of the student-led housing effort. This premise of a deliverable output (a home) at the end of a prescribed two-semester period caused the team to become very product-oriented and less process-oriented.

This product focus reduced opportunities for innovations in process that would have served future homeowners, like the process to identify families who need a home, getting them qualified for home loans, identifying an in-country builder and training residents to maintain homes after possession. The key to sustainable housing for Hondurans is more about incremental innovation in process, i.e., doing things differently in a way that can be locally-owned, than delivery of a product, i.e., a home with a sustainable design. When we focus on the product, we often deliver something that may be innovative by our standards, but is unrepeatable or even undesirable by beneficiaries and local builders who will actually propagate the innovation. Unless we prioritize process from the very beginning, we will underutilize valuable existing community skillsets and participation, (e.g., local masonry techniques and materials) and overemphasize the types of innovative materials or approaches that may be rewarded by engineering professors but are not likely to be locally replicated. Such an approach does not lead to sustainable, organic development.

Even though the pre-travel intent was to engage the community, and especially the family, in the construction of the new home, the focus on product pushed the family and community to the margins. During construction, community members became "spectators", oftentimes an audience for the team as they watched the home being built. Because they were only minimally involved in the design and because some of the materials and construction techniques were unfamiliar, the community became isolated from the "win", reinforcing the perspective in everyone's minds that the effort was "for you", and not "with you". The only notable exception to this was during the 
mixing of concrete, when it was (apparently) so frustrating for more-experienced Hondurans to watch Americans fumble their way through manually mixing batches of concrete on the ground that they offered to help. The US team marveled at the community members' ability to quickly and efficiently produce large batches of concrete on the ground without any container or power device to mix. Furthermore, the co-ed student team never considered that the families watching the effort would never have women doing the same work on the jobsite as men. All of these factors served to further alienate the community from the project, with probable feelings ranging from amusement to helplessness to patronized. The team undertook a 'heroic' effort, working 8-hour days in 100-degree heat for 2 weeks to complete the construction and took with them a sense of pride in 'their' accomplishment. However, local beneficiaries could have been empowered by a much more significant sense of pride if we had slowed the pursuit of tangible "deliverables" and focused on a collaborative design and implementation process.

In Year 2, home design transitioned from steel-stud frame construction with stucco-coated masonry board to standard concrete-masonry unit (CMU)-based construction. This was the result of a second round of interviews that revealed that if the families were investing their own money, homes would have to be built from concrete/CMUs that are perceived to last forever. Having a home constructed from familiar materials and utilizing skillsets common in the community did improve participation in Year 2 somewhat, but the project focus and aggressive timeline for construction meant community participation took lower priority. On a brighter note, the student team's technique of pre-pouring reinforced lintels as headers over doors and windows to simplify and speed construction was viewed favorably by the two Honduran day-laborer masons. They adopted the practice on subsequent home builds and are still using the practice today. Similarly, discussions with a Honduran credit union produced an arrangement allowing a true mortgage loan for $40 \%$ of the materials and labor cost of the home. The 5-year note signed by the recipient family used the property deed as loan collateral. The loan principal was raised by a student online fundraiser and put in a Honduran credit union account in advance. Such seemingly-small innovations in process, based on local context, have much greater replication power. They are also far more likely to allow greater access to housing while simultaneously achieving the deeper goal of local empowerment.

\section{Discussion}

After the 2-year Honduras Sustainable Housing effort, the OSU team became more reflective of community development outcomes and, as a result, is now more community focused. Correspondingly, we have seen an overall shift in our vocabulary from left to right in Figure 1.

First, we sought out a new NGO community development partner in Honduras, one run almost entirely by Hondurans and that will only engage with a community if there is alignment among, and active participation by, all community stakeholders. Indeed, the very initiatives on which the NGO collaborates originate from the community itself, making the NGO a facilitator that works "with them". Instead of focusing on deficiencies or needs of a community from the lens of someone outside, the NGO first considers the assets of a community and its identity. Through a 3 -year process, the community works to restore internal and external broken relationships and uses the resulting unity as a foundation for effective collaboration with a broad array of partners.

Second, we introduced plans for 1-2 graduate students to serve with the NGO in an immersive in-country community development experience during spring, the primary service-learning semester. These persons have considerable presence in the communities during this period and 
keep close contact with the university teams remotely working on community development initiatives. This allows engagement in community discussions and feedback from direct sources to be incorporated, such that initiatives are increasingly collaborative and community-centric.

Third, we established a partner relationship with Zamorano University in Honduras. This will allow blended university project teams to form that have a better overall understanding of the socio-cultural context of development. Projects will have increased follow-up and assessment work done accomplished by Zamorano outside the semester of engagement of the blended teams. As the development schedule takes on more of a year-round nature, it loses its strict academic year ties. Projects become phased, multi-year initiatives that have continuity from year to year. Engagements in ensuing years are responsive to feedback from prior years and projects become less 'end to end' (product-based) and more iterative (process-based). To further reinforce this process-based approach, we have eliminated the capstone affiliation that often has 'end to end' (requirements to product) demands upon student projects.

\section{Summary}

The vocabulary we use to describe community development efforts can be a powerful indicator of our mindset. As we examined our work in Honduras, we found that we had adopted an engineering product development mindset, with all of its constituent vocabulary. An engineer's tendency in problem solving can be to draw a boundary around the technical part of the problem, put that at the center and force the relational aspects to the outside. Examining our vocabulary in this case study allowed us to contrast our methods with more participatory, process-focused community development models, motivating us to re-integrate the technical and relational aspects of engineering and make us better problem solvers in the future.

While the Honduras Sustainable Housing effort did produce two student-designed and largely student-built homes for families in need, it was missing the development of locally owned and sustainable processes that would allow future families to receive homes. A well-built house can provide a family with safety, comfort, and health; a poorly-designed one can collapse on its inhabitants, causing grievous harm with permanent consequences. The processes that we use to achieve our goals have similar repercussions. We have a responsibility to adopt healthy, collaborative, empowering processes that not only improve communities' physical situations, but leave communities more aware of their value and capabilities as a result of our interactions.

\section{References}

[1] Bixler, G., Campbell, J., Dzwonczyk, R., Greene, H. L, Merrill, J., and Passino, K. M. Humanitarian Engineering at The Ohio State University: Lessons Learned in Enriching Education While Helping People, Int. Journal of Service-Learning in Engineering: Humanitarian Engineering and Social Entrepreneurship, pp. 78-96, Fall 2014.

[2] Lucena, J.; Schneider, J. and Leydens, J., Engineering and Sustainable Community Development. Synthesis Lectures on Engineers, Technology and Society, Morgan \& Claypool Publishers: University of Western Australia, pp. 71-75, 2010.

[3] Greene, H. L., An Effective Academic Construct for International Humanitarian Projects in Engineering Education, Proceedings of the 2013 ASEE North-Central Section Conference, Columbus, OH, April 5-6, 2013. 